\title{
Electrokinetic Remediation of Zinc and Copper Contaminated Soil: A Simulation-based Study
}

\author{
Milad Rezaee ${ }^{\mathrm{a}}$, Pourya Kargar Ghomesheh ${ }^{\mathrm{a}}$, Arash Mohammad Hosseini ${ }^{\mathrm{b}}$ \\ ${ }^{a}$ Graduate student in geotechnical engineering, Kharazmi University, Tehran, Iran. \\ ${ }^{b}$ Ph.D. Student, Department of Civil and Environmental Engineering, Temple University, Philadelphia, United States.
}

Received 25 July 2017; Accepted 20 September 2017

\begin{abstract}
Electrokinetic is an effective and innovative method to remediate different kinds of soils, especially low permeable finedgrain soils such as silty and clayey soils. In this method, by applying a direct-current electric field into a contaminated soil resulted in different transport phenomena, the soil is remediated. This paper's objective is to propose a numerical model for Electrokinetic remediation of zinc and copper contaminated soils. Different transport phenomena including ion migration, electroosmosis flow, and diffusion were taken into account in the model. Chemical reactions such as precipitation/dissolution, adsorption onto the soil surface, and water chemical equilibrium were considered as well. Furthermore, instead of simplified boundary conditions (Neumann or Dirichlet) that cannot properly reflect the reality of the Electrokinetic remediation process, the realistic boundary conditions were used with consideration of flux and electrolysis reaction at the electrodes. The simulation results compared with the available experimental data in the literature. The coefficient of determination and the index of agreement indicated that the present model is consistent with the tests' results. Thus, the assumptions considered in the present study are acceptable.
\end{abstract}

Keywords: Electrokinetic; Numerical Model; Zinc; Copper; Chemical Reactions; Soil Remediation.

\section{Introduction}

Soil pollution is a serious problem for environmentalists all over the world. Different kinds of contaminants threat soils and sediments. Several techniques have been developed to purify soils and sediments based on physicochemical, thermal, and biological methods [1]. However, they are often found to be costly, energy intensive, ineffective, and could themselves create other adverse environmental impacts when dealing with difficult subsurface and contaminant conditions [2]. Electrokinetic remediation (EKR) is an innovative method consists of the application of a direct-current (DC) electric field into a soil, producing different transport phenomena through the porous medium. Besides remediation purposes, in civil engineering, the use of electric gradients through clayey soils is a classical way to stabilize large excavations [3]. Electrokinetic has been used for soil consolidation (Electroosmosis consolidation) [4-6] and soil stabilization and improvement [7]. During the EKR, the applied current causes oxidation and reduction at the anode and cathode, respectively and then leads to a series of coupled transport phenomena such as ionic migration, electroosmosis, and electrophoresis. Consequently, the pollutants are enriched near the electrodes and removed from the soil [8]. Ionic migration is the transport of charged complexes under an electric field. Electroosmosis is the movement of pore water through a porous medium of soils as a subsequence of the electric field. Electrophoresis is the transport of charged colloidal size particles and bound contaminants under electric field [2].

\footnotetext{
* Corresponding author: geo_miladrezaee@yahoo.com

DOI: http://dx.doi.org/10.21859/cej-03096

$>$ This is an open access article under the CC-BY license (https://creativecommons.org/licenses/by/4.0/).

(C) Authors retain all copyrights.
} 
Mathematical studies are important, because help scientists to understand the feasibility of their models and to explain the fundamental theories. Various EKR mathematical models have been proposed to increase comprehending about the theory of EKR and help scholars to increase EKR efficiency and develop efficient experimental frameworks. Here, a list of mathematical studies which have been proposed for EKR is presented. Jacobs and Probstein proposed a twodimensional mathematical model and numerical code for phenol removal from kaolin clay under an electric field. They reported good agreement between their model and experimental observation which confirmed the theoretical basis of their model [9]. Chi and Lui developed a mathematical model for Electrokinetic remediation of heavy metal contaminated soil. They assumed that diffusion and ionic migration were the dominant transport forces and according to their model, cadmium ions were ultimately removed from the soil [10]. Harris et al. developed a one-dimensional Electrokinetic model to simulate the transport of cesium and strontium ions through a concrete disc, which indicated a good agreement between the experimental and simulation results [11]. Kim et al. generated two numerical models to simulate the EKR of cadmium and lead contaminated kaolinite soils. Their simulation results showed the capability of their model to simulate the experimental measurement $[12,13]$. Park et al. proposed a numerical model for EKR of phenol-contaminated kaolinite and they reported good agreement between the model and the experiment [14]. VeredaAlonso et al. developed a two-dimensional numerical model to simulate the Electrokinetic remediation of copper spiked kaolin clay. They reported that the model simulation results were consistent with the lab scale experimental test [15].

Amrate and Akretche modeled the EKR of lead-contaminated soil enhanced by the disodium salt of ethylenediaminetetraacetic (EDTA) and reasonable agreement between their model and the experiment were observed [16]. Mascia et al. modeled remediation of cadmium-contaminated kaolinite clay under EKR process. They considered surface reactions and claimed that their model could simulate the experiment accurately [17]. Al-Hamdan and Reddy developed a one-dimensional transport model incorporated with geochemical reactions in order to predict the transport of heavy metals in the soil during the unenhanced EKR. They reported good agreement between the simulation results and the experimental measurements [18]. Paz-Garcia et al. introduced a finite element numerical implementation based on Petrov-Galerkin scheme for Nernst-Planck-Poisson system of equations for the EKR. They stated that their model was capable of simulating the EKR process in both constant current density or in the constant difference of voltage [19]. Yeung et al. simulated the EKR of lead-contaminated soil and they stated that their simulation results were in a good agreement with the experimental data [20]. Paz-Garcia et al. modeled the transport of chemical species in porous material of soil. Their results showed an overestimation and they mentioned that this result could have been due to the miscalculation of electric field strength, effective ionic mobility, and/or improper handling of soil pore fluid chemistry [21]. Miao and Pan simulated the EKR of nuclear waste-contaminated (uranium dioxide) soil and they reported acceptable agreement between their model and the experiment [22]. Asadollahfardi et al. proposed a numerical model for unenhanced EKR of lead-contaminated soil and they reported that their model results were in a good agreement with the experiments [23].

The objective of this paper is to present a theoretical and mathematical model to describe Electrokinetic transport in a contaminated-soil. For the purpose of numerical simulation, an implicit finite difference (Crank-Nicolson) was used to simulate EKR of zinc and copper contaminated soils. We utilized an implicit finite difference, because most of the proposed Electrokinetic models have used finite element methods or explicit finite difference methods. In addition; proposed EKR models based on implicit finite difference used restrictive simplification assumption such as implementing Dirichlet and Neumann boundary conditions without considering flux or electrolysis reactions at the boundaries which do not reflect the reality of the EKR process $[18,16]$. Thus, in the present study, the realistic boundary conditions with considering the impact of flux and electrolysis reactions were employed. Moreover, different chemical reactions including precipitation/dissolution, adsorption, and water chemical equilibrium were considered in the models. The models' results compared with the existing data in the literature.

\section{Materials and Method}

\subsection{The Modeled System}

The EKR test modeled in this study is based on the tests reported by [24] for the removal of zinc and copper from the silty clayey soil in two distinctive experiments. The experimental setup consists of a direct current power supply (500 $\mathrm{V}$ and $5 \mathrm{~A}$ ), an Electrokinetic unit, electrodes, connection cables, and two water tanks. The Electrokinetic unit is made up of Plexiglas and has three main parts: anode, soil, and cathode. The rectangular Electrokinetic unit has $10 \mathrm{~cm} \times 10$ $\mathrm{cm} \times 20 \mathrm{~cm}$ dimensions as depicted in Figure 1. The sidewalls of the anode and the cathode compartments have holes to provide electroosmotic flow. Also, the surfaces of these sidewalls were covered with filter paper to prevent soil passage into the electrode compartments. Both anode and cathode compartments were open at the top to release the electrolysis gases. Two identical graphite plates, with dimensions of $8 \mathrm{~cm} \times 12 \mathrm{~cm} \times 1.5 \mathrm{~cm}$, were used for the anode and the cathode electrodes [24]. The middle part of the Electrokinetic unit (soil part) was filled with a silty clayey soil which was spiked for the first test with $\mathrm{Zn}\left(\mathrm{NO}_{3}\right)_{2}$ and for the second test $\mathrm{Cu}\left(\mathrm{NO}_{3}\right)_{2}$ solutions. For the preparation of the contaminated soils, the soil was added to copper and zinc solutions. After that, the soil mixture was mixed for an hour and allowed to settle 
down for more than 2 days. After draining the additional water in the soil, the soil was used in the EKR test [24]. Table 1. shows the experimental data of the test.

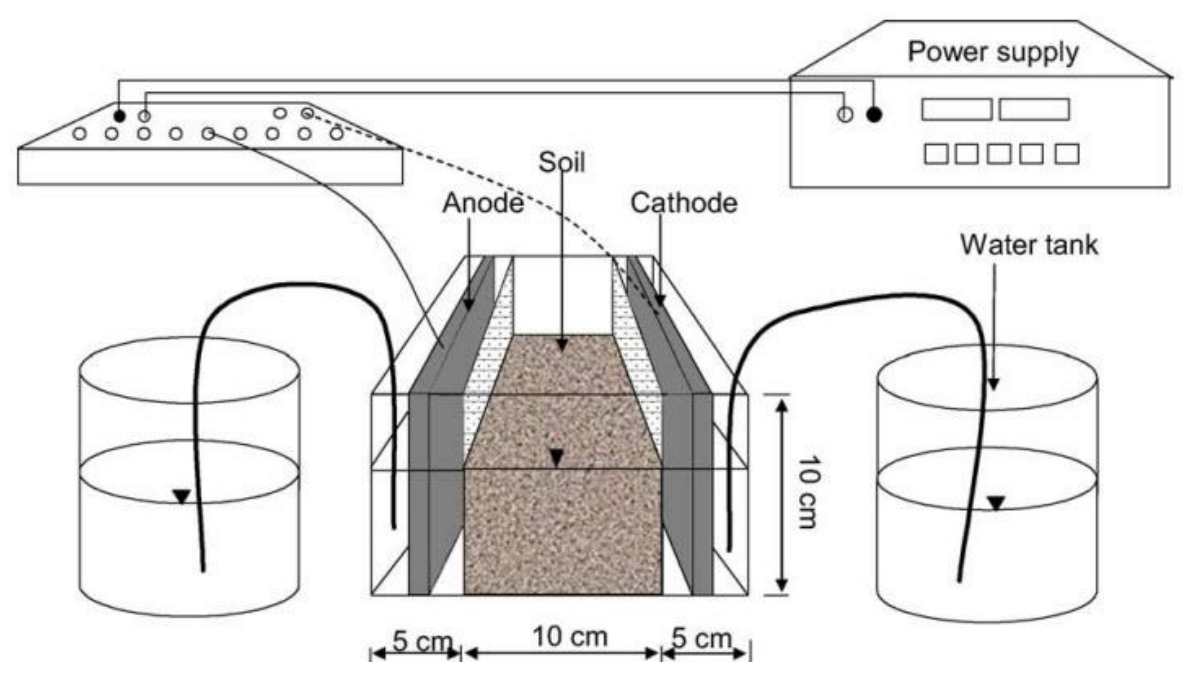

Figure 1. Schematic of the experimental apparatus [24]

Table 1. Experimental data of the test [24]

\begin{tabular}{|c|c|c|}
\hline & Experiment 1 & Experiment 2 \\
\hline Soil specimen & \multicolumn{2}{|c|}{ Silty Clayey Soil } \\
\hline Contamination & $\mathrm{Zn}\left(\mathrm{NO}_{3}\right)_{2}$ & $\mathrm{Cu}\left(\mathrm{NO}_{3}\right)_{2}$ \\
\hline Initial concentration & $158.12 \mathrm{ppm}$ & $53.44 \mathrm{ppm}$ \\
\hline Length of soil cell (cm) & \multicolumn{2}{|c|}{10} \\
\hline Electrical potential (V) & \multicolumn{2}{|c|}{25} \\
\hline Test duration (hr) & \multicolumn{2}{|c|}{30} \\
\hline Anode purging solution & Distilled Water & Distilled Water \\
\hline Cathode purging solution & Distilled Water & Distilled Water \\
\hline
\end{tabular}

\subsection{Transport Phenomenon}

In the present study the following assumptions were taken into account in order to generate the mathematical model:

(1) The modelled soil porous media was considered homogeneous and saturated;

(2) Redox reaction was considered merely at the electrodes;

(3) Instantaneous equilibrium was assumed locally within the time scale of transport for all chemical reactions;

(4) The electrode dissolution was not taken into account;

(5) The movement of water under hydraulic gradient was not taken into consideration (no hydraulic head existed in the system);

(6) Isothermal conditions were assumed;

(7) Electrophoresis was not considered;

(8) The geometry of the modelled system was considered to be one-dimensional.

The present model took into consideration different transport phenomena of the contaminants in the soil during Electrokinetic remediation: advection due to the water movement under electrical potential gradient; diffusion due to concentration gradients; and ionic migration due to the movement of charged ions toward oppositely charged electrodes. Therefore, a set of partial differential equations (PDEs) and algebraic equations were used to explain the transport of the target species under mentioned transport mechanism, which for the first experiment were: $\mathrm{H}^{+}, \mathrm{OH}^{-}, \mathrm{Zn}^{2+}$, and $\mathrm{NO}_{3}^{-}$and 
for the second experiment were: $\mathrm{H}^{+}, \mathrm{OH}^{-}, \mathrm{Cu}^{2+}$, and $\mathrm{NO}_{3}^{-}$.

The flow of chemical species $i$ under EKR process can be defined as a combination of diffusion, electroosmosis, and ionic migration [25-27],

$$
\begin{aligned}
& \mathrm{J}_{i}=-D_{i}^{\text {eff }} \nabla c_{i}-c_{i}\left(u_{i}^{\text {eff }}+k_{e o}\right) \nabla \emptyset \\
& D_{i}^{\text {eff }}=n \tau D_{i}
\end{aligned}
$$

Where $D_{i}^{\text {eff }}\left(\mathrm{m}^{2} \mathrm{~s}^{-1}\right)$ is the effective diffusion coefficient, $\mathrm{n}(-)$ is the porosity of the soil, $\tau$ is the tortuosity factor, $u_{i}^{\text {eff }}$ $\left(\mathrm{m}^{2} \mathrm{~V}^{-1} \mathrm{~s}^{-1}\right)$ is the effective ion mobility, $k_{e o}\left(\mathrm{~m}^{2} \mathrm{~V}^{-1} \mathrm{~s}^{-1}\right)$ is the electroosmotic permeability, $\varnothing(\mathrm{V})$ is the electrical potential, and $c_{i}\left(\mathrm{~mol} \mathrm{~m}^{-3}\right)$ is the concentration. Effective ionic mobility is calculated based on the Nernst-Einstein relation [26-28]:

$u_{i}^{\text {eff }}=\frac{z_{i} F}{R T} D_{i}^{\text {eff }}$

Where $z_{i}$ is the ionic charge of the species; $F\left(\mathrm{C} \mathrm{mol}^{-1}\right)$ is the Faraday constant; $R\left(\mathrm{~K}^{-1} \mathrm{~mol}^{-1}\right)$ is the ideal gas constant, and $T(\mathrm{~K})$ is the absolute temperature. By using the law of mass conservation, the chemical species concentration are described using a system of differential and algebraic equations consisting $N$ mass balance, one for each chemical species and the electroneutrality condition, which are presented in Equations 4 and 5,

$n \frac{\partial c_{i}}{\partial t}=-\nabla \cdot J_{i}+n G_{i} ; i=1,2, \ldots, N$

$$
\sum_{i=1}^{N} c_{i} z_{i}=0
$$

Where $G_{i}=G_{i}^{a d}+G_{i}^{p}+G_{i}^{a q}$ in which $G_{i}\left(\mathrm{~mol} \mathrm{~m}^{-3} \mathrm{~s}^{-1}\right)$ is consumptionlproduction $i$ th aqueous chemical species due to chemical reactions (as e.g. adsorption, precipitation, and ionization). Where $G_{i}^{a q}$ is the production rate of the $i$ th aqueous chemical species because of an aqueous phase reaction; and $G_{i}^{a d}$ is the production rate of the $i$ th aqueous chemical species due to an adsorption reaction; and $G_{i}^{p}$ is the production rate of the $i$ th aqueous chemical species because of a precipitation reaction. In the mathematical model of ionic diffusion used, we used macroscopic equations (1) to (4) where the influence of the physical phenomena at the microscopic and nanoscopic scales is included in the effective diffusion coefficient (Eq. 2) through the tortuosity factor [29]. In the present study the electric field was assumed to be constant during the simulation $[18,23]$.

\subsection{Chemical Reaction}

\subsubsection{Electrolysis Reaction}

In the present model, we assumed that water electrolysis takes place at the electrodes; water oxidation at the anode and reduction at the cathode, as

$\mathrm{H}_{2} \mathrm{O} \leftrightarrows \frac{1}{2} \mathrm{O}_{2}+2 \mathrm{H}^{+}+2 \mathrm{e}^{-} ; \quad E^{0}=-1.229 \mathrm{~V}$
$2 \mathrm{H}_{2} \mathrm{O}+2 \mathrm{e}^{-} \leftrightarrows \mathrm{H}_{2}+2 \mathrm{OH}^{-} ; \quad E^{0}=-0.828 \mathrm{~V}$

Where $\mathrm{E}^{0}$ is the standard redox potential of the half reaction.

The electrolysis reactions produce the injection of protons and hydroxide ions from the anode and the cathode respectively $[2,19]$. No other competitive electrode reactions were taken into account in the model.

\subsubsection{Adsorption Reaction}

Adsorption is the net accumulation of chemical species at the interface between a solid-phase and fluid phase [30]. It is considered that the adsorption of heavy metal ions and complexes on clay minerals occurs as a result of ion exchange, surface complexation, hydrophobic interaction, and electrostatic interaction [31]. Factors such as $\mathrm{pH}$, nature, and concentration of a substrate and adsorbing ion, ionic strength, and the presence of complexing ions, have an impact on the extent of an adsorption $[32,33]$.

A linear function is the most widely used adsorption isotherm equation. The adsorption isotherm equation is conventionally expressed in terms of the distribution coefficient: 


$$
\begin{aligned}
& G_{i}^{a d}=-\frac{\rho}{n} \frac{\partial c_{i}^{a d}}{\partial t}=-\frac{\rho}{n} \frac{\partial c_{i}^{a d}}{\partial c_{i}} \frac{\partial c_{i}}{\partial t} \\
& \partial c_{i}^{a d} / \partial c_{i}=K_{d i} \\
& R_{d i}=1+\frac{\rho K_{d i}}{n} \\
& n R_{d i} \frac{\partial c_{i}}{\partial t}=D_{i}^{\mathrm{eff}} \frac{\partial^{2} c_{i}}{\partial x^{2}}+\left(u_{i}^{\mathrm{eff}}+k_{e o}\right) \frac{\partial c_{i}}{\partial x} \frac{\partial \emptyset}{\partial x}+n\left(G_{i}^{a q}+G_{i}^{p}\right) ; i=1,2, \ldots, N
\end{aligned}
$$

Where $c_{i}^{a d}\left(\mathrm{~mol} \mathrm{~kg}^{-1}\right)$ is the amount of solute absorbed/adsorbed onto a unit weight of solid, $c_{i}\left(\mathrm{~mol} \mathrm{~m} \mathrm{~m}^{-3}\right)$ is the concentration of solute, $K_{d i}\left(\mathrm{~m}^{3} \mathrm{~kg}^{-1}\right)$ is the distribution coefficient, $\rho$ is the bulk dry density of the soil and $R_{d i}$ is the retardation factor of the specific chemical species. Equation 11. shows the transport formula of chemical species $i$ with considering retardation factor and setting electric field constant over the simulation time.

\subsubsection{Water Chemical Equilibrium and Precipitation Reaction}

After calculating transport equations numerically at each time step, the equilibrium concentration of each species is calculated from the last value obtained from the transport equation as described before. Therefore, water chemical equilibrium (Equation 12) was considered for the models. Moreover, in experiment 1, the precipitation reaction between zinc and hydroxide and in experiment 2 the precipitation reaction between copper and hydroxide were taken into account in the models.

$$
\begin{aligned}
& \mathrm{H}^{+}+\mathrm{OH}^{-} \leftrightarrows \mathrm{H}_{2} \mathrm{O} \quad K_{w}=\left[\mathrm{H}^{+}\right]\left[\mathrm{OH}^{-}\right]=10^{-14} \\
& \mathrm{Cu}^{2+}+2 \mathrm{OH}^{-} \leftrightarrows \mathrm{Cu}(\mathrm{OH})_{2} \quad K_{S p}=\left[\mathrm{Cu}^{2+}\right]\left[\mathrm{OH}^{-}\right]^{2}=2.2 \times 10^{-20} \\
& \mathrm{Zn}^{2+}+2 \mathrm{OH}^{-} \leftrightarrows \mathrm{Zn}(\mathrm{OH})_{2} \quad K_{s p}=\left[\mathrm{Zn}^{2+}\right]\left[\mathrm{OH}^{-}\right]^{2}=5.0 \times 10^{-17}
\end{aligned}
$$

$\mathrm{K}_{\mathrm{w}}$ is the water equilibrium constant and $\mathrm{K}_{\mathrm{sp}}$ is the solubility product equilibrium constant of the precipitation reaction.

\subsection{Numerical Analysis}

To numerically solve one-dimensional transport equation under EKR process, the introduction of two boundary conditions and one initial condition for each species is necessary. The transport equation for each chemical species along with specific boundary conditions at the electrodes for each ion is presented. Retardation factor was taken into account for all chemical species except hydroxide which is a negative electric charge species. The clayey soils have negative surface charge, so consideration of adsorption for hydroxide would be meaningless.

Zinc:

$$
\begin{aligned}
& n R_{d Z n} \frac{\partial c_{Z n}}{\partial t}=D_{Z n}^{\mathrm{eff}} \frac{\partial^{2} c_{Z n}}{\partial x^{2}}+\left(u_{Z n}^{\mathrm{eff}}+k_{e o}\right) \frac{\partial c_{Z n}}{\partial x} \frac{\partial \emptyset}{\partial x}+n G_{Z n}^{p} \\
& -D_{Z n}^{\mathrm{eff}} \frac{\partial c_{Z n}}{\partial x}+\left.\left(k_{e o}+u_{Z n}^{\mathrm{eff}}\right)\left(-\frac{\partial \emptyset}{\partial x}\right) c_{Z n}\right|_{x=\text { Anode }}=0 \\
& -D_{Z n}^{\mathrm{eff}} \frac{\partial c_{Z n}}{\partial x}+\left.\left(k_{e o}+u_{Z n}^{\mathrm{eff}}\right)\left(-\frac{\partial \emptyset}{\partial x}\right) c_{Z n}\right|_{x=\text { Cathode }}=c_{Z n} k_{e o}\left(-\frac{\partial \emptyset}{\partial x}\right)
\end{aligned}
$$

Copper:

$$
\begin{aligned}
& n R_{d C u} \frac{\partial c_{C u}}{\partial t}=D_{C u}^{\mathrm{eff}} \frac{\partial^{2} c_{C u}}{\partial x^{2}}+\left(u_{C u}^{\mathrm{eff}}+k_{e o}\right) \frac{\partial c_{C u}}{\partial x} \frac{\partial \emptyset}{\partial x}+n G_{C u}^{p} \\
& -D_{C u}^{\mathrm{eff}} \frac{\partial c_{C u}}{\partial x}+\left.\left(k_{e o}+u_{C u}^{\mathrm{eff}}\right)\left(-\frac{\partial \emptyset}{\partial x}\right) c_{C u}\right|_{x=A n o d e}=0
\end{aligned}
$$


$-D_{C u}^{\mathrm{eff}} \frac{\partial c_{C u}}{\partial x}+\left.\left(k_{e o}+u_{C u}^{\mathrm{eff}}\right)\left(-\frac{\partial \emptyset}{\partial x}\right) c_{C u}\right|_{x=\text { Cathode }}=c_{C u} k_{e o}\left(-\frac{\partial \emptyset}{\partial x}\right)$

Proton:

$$
\begin{aligned}
& n R_{d H^{+}} \frac{\partial c_{H^{+}}}{\partial t}=D_{H^{+}}^{\mathrm{eff}} \frac{\partial^{2} c_{H^{+}}}{\partial x^{2}}+\left(u_{H^{+}}^{\mathrm{eff}}+k_{e o}\right) \frac{\partial c_{H^{+}}}{\partial x} \frac{\partial \emptyset}{\partial x}+n G_{H^{+}}^{a q} \\
& -D_{H^{+}}^{\mathrm{eff}} \frac{\partial c_{H^{+}}}{\partial x}+\left.\left(k_{e o}+u_{H^{+}}^{\mathrm{eff}}\right)\left(-\frac{\partial \emptyset}{\partial x}\right) c_{H^{+}}\right|_{x=\text { Anode }}=c_{0}^{H^{+}} k_{e o}\left(-\frac{\partial \emptyset}{\partial x}\right)+\frac{I}{F} \\
& -D_{H^{+}}^{\mathrm{eff}} \frac{\partial c_{H^{+}}}{\partial x}+\left.\left(k_{e o}+u_{H^{+}}^{\mathrm{eff}}\right)\left(-\frac{\partial \emptyset}{\partial x}\right) c_{H^{+}}\right|_{x=\text { Cathode }}=c_{H^{+}} k_{e o}\left(-\frac{\partial \emptyset}{\partial x}\right)
\end{aligned}
$$

Hydroxide:

$$
\begin{aligned}
& n \frac{\partial c_{O H^{-}}}{\partial t}=D_{O H^{-}}^{\mathrm{eff}} \frac{\partial^{2} c_{O H^{-}}}{\partial x^{2}}+\left(u_{O H^{-}}^{\mathrm{eff}}+k_{e o}\right) \frac{\partial c_{O H^{-}}}{\partial x} \frac{\partial \emptyset}{\partial x}+n G_{O H^{-}}^{a q} \\
& -D_{O H^{-}}^{\mathrm{eff}} \frac{\partial c_{O H^{-}}}{\partial x}+\left.\left(k_{e o}+u_{O H^{-}}^{\mathrm{eff}}\right)\left(-\frac{\partial \emptyset}{\partial x}\right) c_{O H^{-}}\right|_{x=\text { Anode }}=c_{0}^{O H^{-}} k_{e o}\left(-\frac{\partial \emptyset}{\partial x}\right) \\
& -D_{O H^{-}}^{\mathrm{eff}} \frac{\partial c_{O H^{-}}}{\partial x}+\left.\left(k_{e o}+u_{O H^{-}}^{\mathrm{eff}}\right)\left(-\frac{\partial \emptyset}{\partial x}\right) c_{O H^{-}}\right|_{x=\text { Cathode }}=c_{O H^{-}} k_{e o}\left(-\frac{\partial \emptyset}{\partial x}\right)-\frac{I}{F}
\end{aligned}
$$

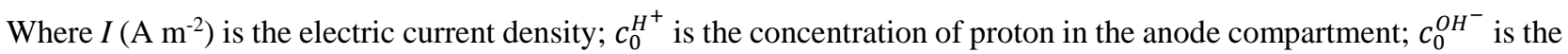
concentration of hydroxide in the anode compartment; $R_{d z n}$ is the zinc retardation factor; $R_{d c u}$ is the copper retardation factor; and $R_{d H}$ is the proton retardation factor. In order to generate boundary conditions, it was assumed that whole electric current was expended in the generation of $\mathrm{H}^{+}$at the anode and $\mathrm{OH}^{-}$at the cathode. By imposing electroneutrality into the system of equations, it is possible to achieve $\mathrm{NO}_{3}^{-}$concentration at each time and space by:

$C_{N O}=-\frac{\sum_{j=1}^{3} z_{j} c_{j}}{z_{N O}}$

The initial condition for zinc, copper, proton, and hydroxide are represented in Table 2.

Table 2. Initial condition of target species

\begin{tabular}{cc}
\hline Species & Initial condition \\
\hline Zinc & $2.88 \times 10^{-4}(\mathrm{~mol} / \mathrm{lit})$ \\
Copper & $9.65 \times 10^{-5}(\mathrm{~mol} / \mathrm{lit})$ \\
Proton & $10^{-5}(\mathrm{~mol} / \mathrm{lit})$ \\
Hydroxide & $10^{-9}(\mathrm{~mol} / \mathrm{lit})$ \\
\hline
\end{tabular}

Crank-Nicolson, which is an implicit finite difference method, was implemented to solve the system of PDEs numerically. Based on von Neumann stability analysis, this method is unconditionally stable [34]. The discretized form of Eq.11 by implementing Crank-Nicolson method to discretize the equation is:

$$
\begin{aligned}
& \frac{c_{k}^{n+1}-c_{k}^{n}}{\Delta t}=0.5 A\left(\frac{c_{k-1}^{n}-2 c_{k}^{n}+c_{k+1}^{n}}{\Delta x^{2}}+\frac{c_{k+1}^{n+1}-2 c_{k}^{n+1}+c_{k+1}^{n+1}}{\Delta x^{2}}\right)+0.5 B\left(\frac{c_{k+1}^{n}-c_{k-1}^{n}}{2 \Delta x}+\frac{c_{k+1}^{n+1}-c_{k-1}^{n+1}}{2 \Delta x}\right) \\
& -(S+0.5 C) c_{k-1}^{n+1}+2(1+S) c_{k}^{n+1}-(S-0.5 C) c_{k+1}^{n+1}=(S+0.5 C) c_{k-1}^{n}+2(1-S) c_{k}^{n}+(S-0.5 C) c_{k+1}^{n} \\
& L c^{n+1}=T c^{n}
\end{aligned}
$$




$$
L=\left(\begin{array}{cccccc}
L_{1,1} & L_{1,2} & 0 & 0 & \ldots & 0 \\
-(S+0.5 C) & 2(1+S) & -(S-0.5 C) & \ddots & \ddots & \ddots \\
0 & -(S+0.5 C) & 2(1+S) & -(S-0.5 C) & \ddots & \ddots \\
0 & \ddots & \ddots & \ddots & \ddots & \ddots \\
\vdots & \ddots & \ddots & -(S+0.5 C) & 2(1+S) & -(S-0.5 C) \\
0 & \ddots & \ddots & \ddots & L_{N X, N X-1} & L_{N X, N X}
\end{array}\right)_{N X \times N X}
$$

$$
T=\left(\begin{array}{cccccc}
T_{1,1} & T_{1,2} & 0 & 0 & \cdots & 0 \\
(S+0.5 C) & 2(1-S) & (S-0.5 C) & \ddots & \ddots & \ddots \\
0 & (S+0.5 C) & 2(1-S) & (S-0.5 C) & \ddots & \ddots \\
0 & \ddots & \ddots & \ddots & \ddots & \ddots \\
\vdots & \ddots & \ddots & (S+0.5 C) & 2(1-S) & (S-0.5 C) \\
0 & \ddots & \ddots & \ddots & T_{N X, N X-1} & T_{N X, N X}
\end{array}\right)_{N X \times N X}
$$

Where $A=D_{i}^{\mathrm{eff}} / R_{d i} n ; B=\frac{\left(u_{i}^{\mathrm{eff}}+k_{e o}\right)}{R_{d i} n} \frac{\partial \emptyset}{\partial x} ; S=A \frac{\Delta t}{\Delta x^{2}} ; C=B \frac{\Delta t}{\Delta x} ; \Delta x$ and $\Delta t$ are the spatial and the time increments, respectively. The elements, including; $L_{1,1}, L_{1,2}, L_{N X, N X-1}, L_{N X, N X}, T_{1,1}, T_{1,2}, T_{N X, N X-1}$ and $T_{N X, N X}$, were generated from the boundary conditions. Table 3 . illustrates the input parameters in the present model.

\begin{tabular}{|c|c|}
\hline Parameter & Value \\
\hline Length of soil cell (cm) & 10 \\
\hline Test duration (hr) & 30 \\
\hline Spatial increment (mm) & 0.1 \\
\hline Time increment (s) & 10 \\
\hline Porosity & 0.5 \\
\hline Tortuosity factor & 0.3 \\
\hline Viscosity of fluid (C V s $\left./ \mathrm{m}^{2}\right)$ & 0.001 \\
\hline Electrical conductivity $(\mathrm{C} / \mathrm{Vm})$ & $7 \times 10^{-10}$ \\
\hline Electroosmotic permeability (m²/Vs) & $5 \times 10^{-9}$ \\
\hline Applied electric field (V) & 25 \\
\hline Faraday's constant $F\left(\mathrm{C} \mathrm{mol}^{-1}\right)$ & 96487 \\
\hline Universal gas constant $R\left(\mathrm{~J} \mathrm{~K}^{-1} \mathrm{~mol}^{-1}\right)$ & 8.314 \\
\hline Zinc retardation factor $R_{d Z}$ & 3 \\
\hline Copper retardation factor $R_{d C}$ & 5.5 \\
\hline Proton retardation factor $R_{d H}$ & 4 \\
\hline$D_{i}$ of $\mathrm{Zn}^{2+}\left(\mathrm{m}^{2} \mathrm{~s}^{-1}\right)$ & $7.03 \times 10^{-10}$ \\
\hline$D_{i}$ of $\mathrm{Cu}^{2+}\left(\mathrm{m}^{2} \mathrm{~s}^{-1}\right)$ & $7.14 \times 10^{-10}$ \\
\hline$D_{i}$ of $\mathrm{H}^{+}\left(\mathrm{m}^{2} \mathrm{~s}^{-1}\right)$ & $93.1 \times 10^{-10}$ \\
\hline$D_{i}$ of $\mathrm{OH}^{-}\left(\mathrm{m}^{2} \mathrm{~s}^{-1}\right)$ & $52.7 \times 10^{-10}$ \\
\hline$D_{i}$ of $\mathrm{NO}_{3}^{-}\left(\mathrm{m}^{2} \mathrm{~s}^{-1}\right)$ & $19 \times 10^{-10}$ \\
\hline
\end{tabular}

Table 3. Input parameters used in Numerical Analysis [35] 


\subsection{Model Accuracy}

The coefficient of determination $\left(\mathrm{R}^{2}\right)$ and index of agreement (IA) indicate the efficiency of simulation predictions. To indicate the accuracy and efficiency of the models, $\mathrm{R}^{2}$ and IA were calculated between our numerical simulation results and experimental measurement. The $\mathrm{R}^{2}$ and IA vary between zero to one. When the $\mathrm{R}^{2}$ and IA approach to one the model is well developed. The $\mathrm{R}^{2}$ and IA formulations are:

$$
\begin{aligned}
& R^{2}=\left(\frac{\sum_{i=1}^{n}\left(O_{i}-\bar{O}\right)\left(P_{i}-\bar{P}\right)}{\sqrt{\sum_{i=1}^{n}\left(O_{i}-\bar{O}\right)^{2}} \sqrt{\sum_{i=1}^{n}\left(P_{i}-\bar{P}\right)^{2}}}\right)^{2} \\
& I A=1-\frac{\sum_{i=1}^{n}\left(O_{i}-P_{i}\right)^{2}}{\sum_{i=1}^{n}\left(\left|P_{i}-\bar{O}\right|+\left|O_{i}-\bar{O}\right|\right)^{2}}
\end{aligned}
$$

Where $\mathrm{O}$ is the observed value (experimental measurement), $\overline{\mathrm{O}}$ is the mean value of $\mathrm{O}, \mathrm{P}$ is the predicted value (numerical simulation result) and $\overline{\mathrm{P}}$ is the mean value of $\mathrm{P}$.

\section{Results and Discussion}

In the unenhanced EKR test due to oxidation at the anode and reduction at the cathode, proton and hydroxide ions are generated in the electrode cells. The electrolysis reaction results in extreme acidic and basic condition at the electrode cells [36]. Figure 2. shows pH in the electrode cells that were predicted by the model for EKR of zinc-contaminated soil. As depicted in Figure 2, the pH after 30 hours reached around 11 in the anode cell and reached around 2 in the cathode cell, this simulation result is aligned with the experimental measurement $[24,37]$. The predicted $\mathrm{pH}$ under the EKR of copper-contaminated soil was similar to simulation result of zinc-contaminated soil and both of them are in agreement with the prediction reported in [14].

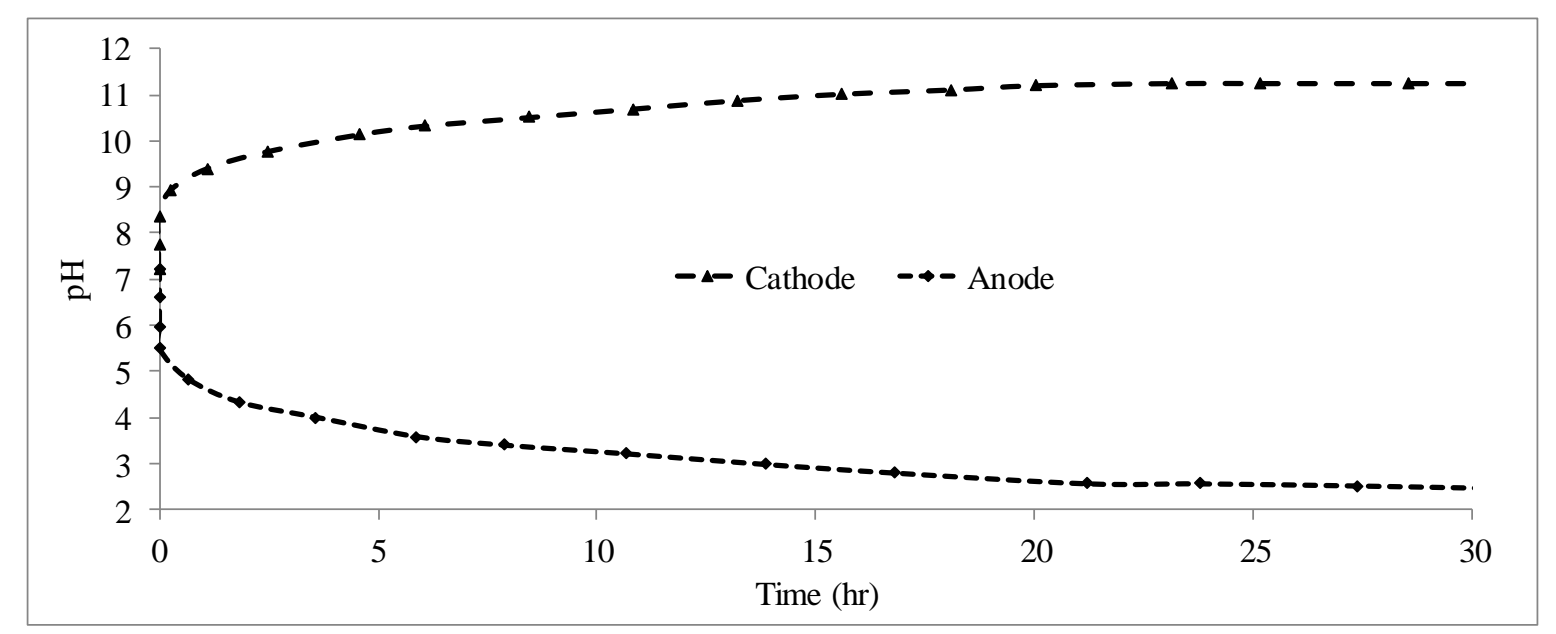

Figure 2. pH in anode and cathode cells predicted by the model

Electrolysis reaction at the electrodes causes proton and hydroxide ions generation. Proton ions transport into the soil sample by ionic migration and electroosmotic flow (electroosmotic flow direction is from the anode to the cathode); also, hydroxide ions transport in the soil by ionic migration. Proton and hydroxide transportation into the soil causes acid and base front movement which results in changing soil $\mathrm{pH}$. When acid and base front meet each other, a jump happens in the $\mathrm{pH}$ profile $[23,38]$ as simulated by the present model for experiment 1 (EKR of zinc-contaminated soil) (Figure 3). The experimental measurement was not available to validate $\mathrm{pH}$ prediction, yet our prediction is consistent with the $\mathrm{pH}$ profile in the soil under unenhanced EKR tests reported by others $[12,13,23]$. In the unenhanced test, $\mathrm{pH}$ of a soil near the anode compartment decreased to 2, and near the cathode compartment increased to values around 11 $[12,13,18]$ which is in agreement with $\mathrm{pH}$ predicted by our model. Furthermore, as Figure 3 . shows, by running the program and passing the time the soil became acidified and this phenomenon is in agreement with studies on EKR tests $[20,21]$. 


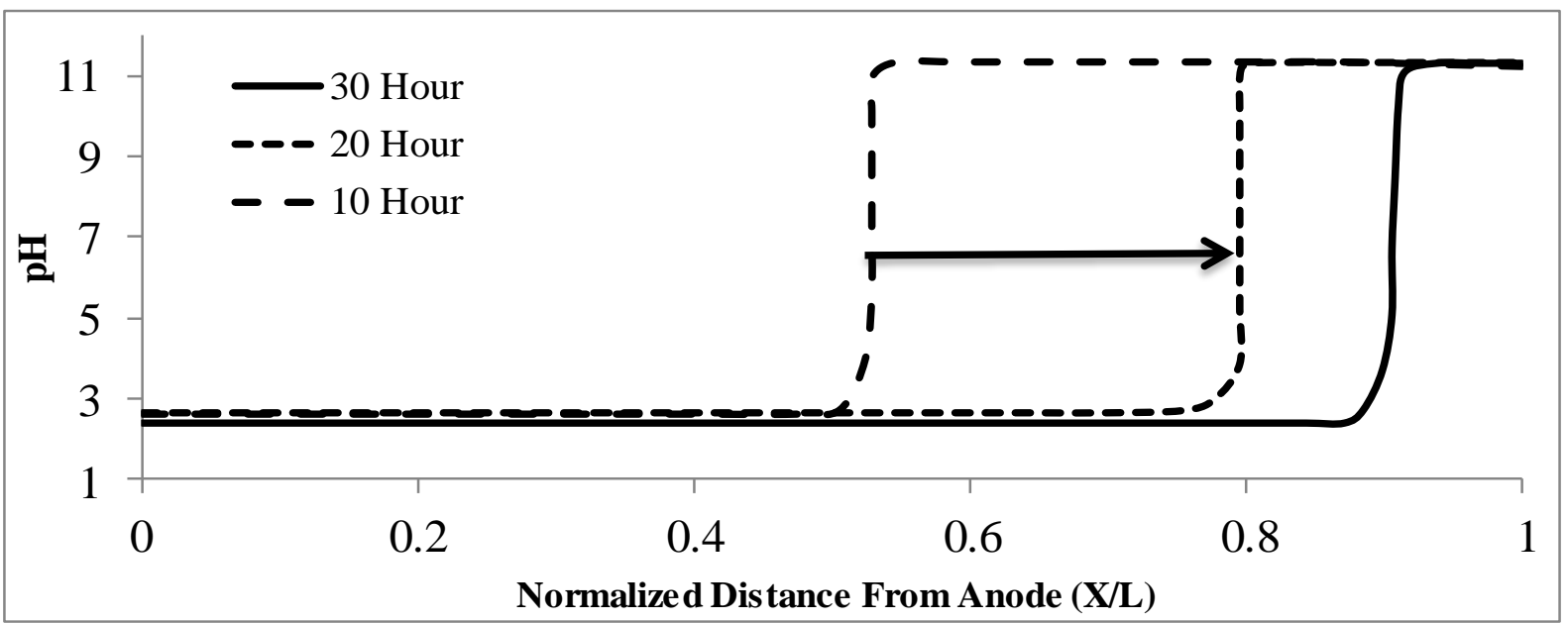

Figure 3. pH predicted in the soil sample

Figure 4. shows the simulation result of zinc concentration profile in the soil. The coefficient of determination $\left(\mathrm{R}^{2}\right)$ and index of agreement (IA) were calculated between the simulation results and the experimental measurements in order to show the accuracy of the model [39]. The $\mathrm{R}^{2}=0.978$ and $\mathrm{IA}=0.969$ calculations indicate that our model was capable of simulating the zinc concentration profile in the soil. Figure 5. illustrates the simulation result of copper concentration profile in the soil. The $\mathrm{R}^{2}=0.953$ and $\mathrm{IA}=0.98$ calculations indicate that our model could predict the copper concentration profile in the soil reasonably. Thus, these results demonstrate that the present model with consideration of transport phenomena such as ionic migration, electroosmosis, and diffusion as well as taking into account the chemical reactions and realistic boundary conditions, could predict the EKR test accurately.

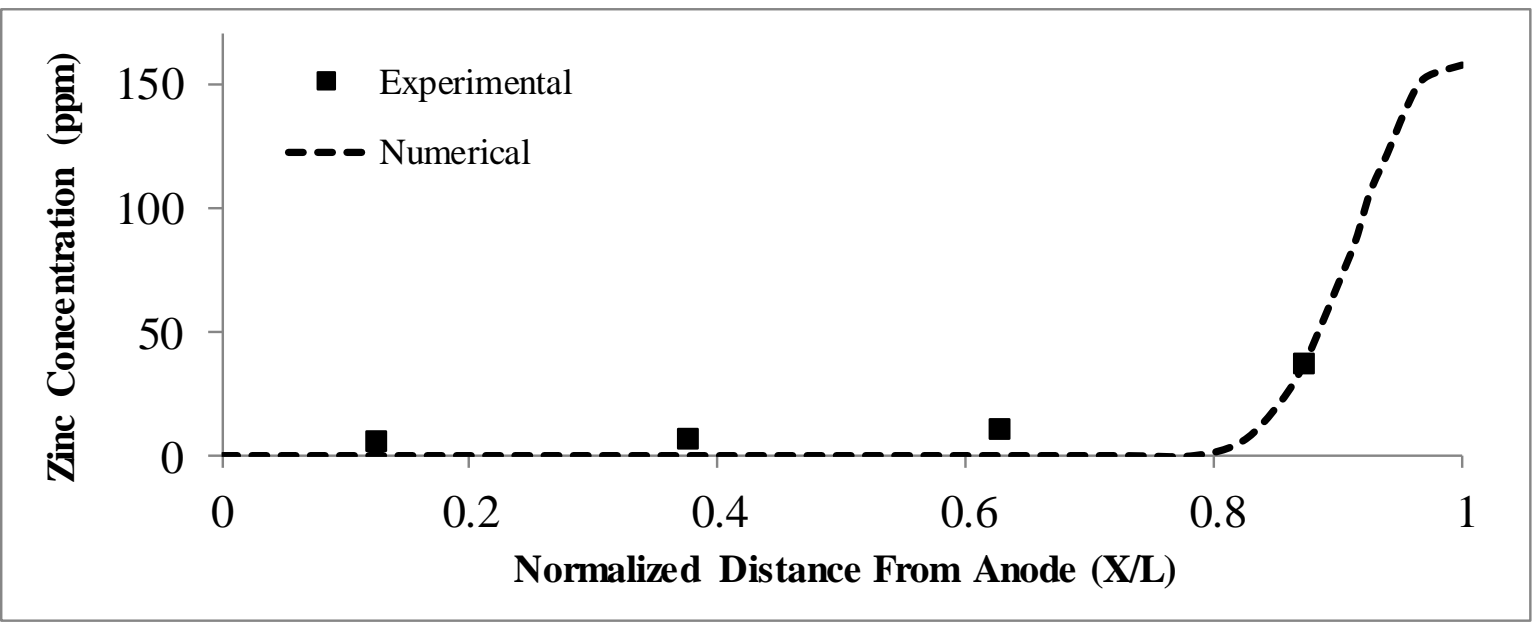

Figure 4. Comparison between predicted and measured zinc concentration

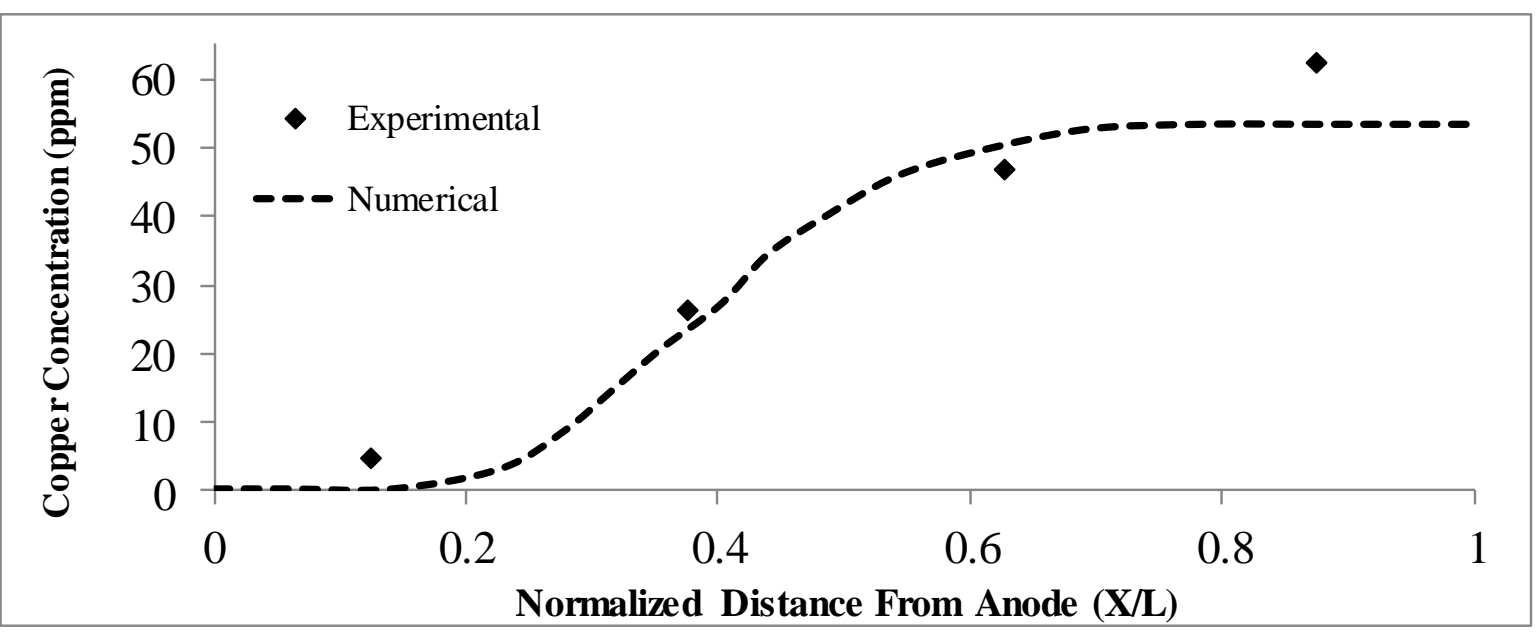

Figure 5. comparison between predicted and measured copper concentration 


\section{Conclusion}

This paper presents a numerical model for EKR of two different contaminated soils. The model was generated on the basis of a set of PDEs and algebraic equations in order to describe the transportation of target species. Different chemical reactions along with considering realistic boundary conditions at the electrodes were applied to the model. The simulation results showed that the proposed model could simulate $\mathrm{pH}$ in the electrode cells and across the soil sample reasonably when the model results were compared with the experimental and mathematical studies which have been reported up to now. The simulation results for zinc and copper concentration profiles which were on the basis of $\mathrm{R}^{2}$ and IA calculation were in a good agreement with the experimental measurements. Therefore, the proposed model with the considered assumption is plausible.

\section{References}

[1] Sharma, H.D. and Reddy, K.R. Geoenvironmental Engineering: Site Remediation, Waste Containment, and Emerging Waste Management Technologies, Wily, 2004.

[2] Reddy, K.R. and Cameselle, C. Electrochemical Remediation Technologies for polluted soils, sediments and groundwater, Wily, 2009.

[3] Lemaire, T. Moyne, C. and Stemmelen, D. Modelling of electro-osmosis in clayey materials including pH effects, Phys. Chem. Earth, vol. 32 (2007): 441-452.

[4] Jeyakanthan, V. and Gnanendran, C. T. Elastoplastic numerical approach for predicting the electro-osmotic consolidation behaviour of soft clays, Can. Geotech. J., 50(2013): 1219-1235.

[5] Yuan, J. and Hicks, M. A. Numerical simulation of elasto-plastic electro-osmosis consolidation at large strain, Acta Geotech., 11(2016): 127-143.

[6] Zhou, Y Deng, D. and Wang, C. Finite-difference model for one-dimensional electro-osmotic consolidation, Comput. Geotech. 54(013): 152-165.

[7] Estabragh, A. R. Naseh, M. and Javadi, A. A. Improvement of clay soil by electro-osmosis technique, Appl. Clay Sci., 95(2014): $32-36$.

[8] Reddy, K. R.and Chinthamreddy, S. Sequentially Enhanced Electrokinetic Remediation of Heavy Metals in Low Buffering Clayey Soils, J. Geotech. Geoenvironmental Eng, 129 (2003): 263-277.

[9] Jacobs, R. A.and Probstein, R. F. Two-dimensional modeling of electroremediation, AIChE J., 42(1996): 1685-1696.

[10] Choi Y. S. and Lui, R. A mathematical model for the electrokinetic remediation of contaminated soil, J. Hazard. Mater., 44(1995): 61-75.

[11] Harris, M. T.. DePaoli, D. W and Ally, M. Modeling the electrokinetic transport of strontium and cesium through a concrete disk, Sep. Purif. Technol., 11(1997): 173-184.

[12] Kim, S.O. Kim, J. J. Yun, S. T. and Kim, K. W. Numerical and experimental studies on Cadmium(II) transport in kaolinite clay under electrical fields, Water, Air Soil Pollut., 150,(2003): 135-162.

[13] Kim, S. Kim, J. Kim, K. and Yun, S. Models and Experiments on Electrokinetic Removal of Pb(II) from Kaolinite Clay, Separation Science and Technology, 39 (2004): 1927-1951.

[14] Park, J.S. Kim, S.O. Kim, K.W. Kim, B.R. and Moon, S.H. Numerical analysis for electrokinetic soil processing enhanced by chemical conditioning of the electrode reservoirs, J. Hazard. Mater., 99 (2003): 71-88.

[15] Vereda-Alonso, C. Rodríguez-Maroto, J. M. García-Delgado, R. A. Gómez-Lahoz, C. and García-Herruzo, F. Two-dimensional model for soil electrokinetic remediation of heavy metals: Application to a copper spiked kaolin, Chemosphere, 54(2004): 895-903.

[16] Amrate S. and Akretche, D. E. Modeling EDTA enhanced electrokinetic remediation of lead contaminated soils, Chemosphere, 60 (2005): 1376-1383.

[17] Mascia, M. Palmas, S. Polcaro, A. M. Vacca, A. and Muntoni, A. Experimental study and mathematical model on remediation of Cd spiked kaolinite by electrokinetics, Electrochim. Acta, 52 (2007): 3360-3365.

[18] Al-Hamdan A. Z. and Reddy, K.R. Electrokinetic Remediation Modeling Incorporating Geochemical Effects,” J. Geotech. Geoenvironmental Eng., 134 (2008): 91-105.

[19] Paz-García, J.M. Johannesson, B. Ottosen, L.M. Ribeiro, A.B. and. Rodríguez-Maroto, J.M. Modeling of electrokinetic processes by finite element integration of the Nernst-Planck-Poisson system of equations, Sep. Purif. Technol., 79 (2011): 183-192.

[20] Yeung, A.T. Hsu, C.N and R. M. Menon, Electrokinetic extraction of lead from kaolinites: I. Numerical modeling, 
Environmentalist, 31 (2011): 26-32.

[21] Paz-Garcia, J.M. Baek, K. Alshawabkeh, I.D. and Alshawabkeh, A.N. A generalized model for transport of contaminants in soil by electric fields., J. Environ. Sci. Health. A. Tox. Hazard. Subst. Environ. Eng., 47 (2012): 308-18.

[22] Miao T. and Pan, T. A Multiphysics Model for Evaluating Electrokinetic Remediation of Nuclear Waste-Contaminated Soils, Water, Air, Soil Pollut., 226 (2015): 77.

[23] Asadollahfardi, G. Rezaee, M. and Tavakoli Mehrjardi, G. Simulation of Unenhanced Electrokinetic Process for Lead Removal from Kaolinite Clay, Int. J. Civ. Eng., 14 (2016): 263-270.

[24] Turer D. and Genc, A. Assessing effect of electrode configuration on the efficiency of electrokinetic remediation by sequential extraction analysis, J. Hazard. Mater., 119 (2005): 167-174.

[25] Mitchell James, K. "Fundamentals of soil behavior." (1993).

[26] Alshawabkeh, Akram Nimer. "Theoretical and Experimental Modeling of Removing Contaminants From Soils by an Electric Field." (1994).

[27] Probstein, Ronald F. Physicochemical hydrodynamics: an introduction. John Wiley \& Sons, 2005.

[28] Irving, B. A., and P. J. Holmes. "The electrochemistry of semiconductors." Academic press, London (1962): 262-294.

[29] Bourbatache, K. Millet, O. and Aït-Mokhtar, A. Ionic transfer in charged porous media. Periodic homogenization and parametric study on 2D microstructures, Int. J. Heat Mass Transf., 55 (2012): 5979-5991.

[30] Sposito, G. "The Chemistry of Soils Oxford Univ." Press, New York, USA (1989).

[31] Hizal, J. and Apak, R. Modeling of cadmium(II) adsorption on kaolinite-based clays in the absence and presence of humic acid, Appl. Clay Sci., 32 (2006): 232-244.

[32] Srivastava, P. Singh, B. and Angove, M. Competitive adsorption behavior of heavy metals on kaolinite, J. Colloid Interface Sci., 290 (2005), 28-38.

[33] Ikhsan, J. Johnson, B. and Wells, J. A Comparative Study of the Adsorption of Transition Metals on Kaolinite., J. Colloid Interface Sci., 217 (1999): 403-410.

[34] Fletcher, Clive AJ. "Computational techniques for fluid dynamics. Volume 1-Fundamental and general techniques. Volume 2Specific techniques for different flow categories." In Berlin and New York, Springer-Verlag, 1988, p. Vol. 1, 418 p.; vol. 2, 493 p., vol. 1. 1988.

[35] Rezaee, M. Numerical Modeling of Electrokinetic Remediation of Heavy Metal Contaminated Kaolinite Soil. MS.c. Thesis, Kharazmi University, 2014.

[36] Asadollahfardi, G. Nasrollahi Gisel, M. and Rezaee, M. Electrochemical Remediation Technology : Fundamentals, Benefits and Challenges First international symposium on environmental and water resource engineering, 2015.

[37] Asadollahfardi, G. Nasrollahi, M. Rezaee, M. and Khodadadi Darban, A. Nickel removal from low permeable kaolin soil under unenhanced and EDTA-enhanced electrokinetic process, Adv. Environ. Res., 2(2017): 147-158.

[38] M. Rezaee, G. Asadollahfardi, Nasrollahi Gisel, M. Mathematical modeling of electrochemical soil decontamination, 10th international congress on civil engineering, 2015.

[39] Asadollahfardi, G. Darban, A. K. Noorifar, N. and Rezaee, M. Mathematical simulation of surfactant flushing process to remediate diesel contaminated sand column, Adv. Environ. Res., 5(2016): 213-224. 